
\title{
28 Research Square \\ Epidemiology and etiology of lower limb injuries in Iranian recreational runners
}

\section{Seyed Hamed Mousavi ( $\nabla$ s.h.mousavi@umcg.nl)}

Universitair Medisch Centrum Groningen https://orcid.org/0000-0003-2906-2101

Juha Hijmans

Universitair Medisch Centrum Groningen

Hooman Minoonejad

University of Tehran

Reza Rajabi

University of Tehran

\section{Behrooz Alizadeh}

Universitair Medisch Centrum Groningen

Johannes Zwerver

Rijksuniversiteit Groningen

\section{Research article}

Keywords: running, injury, risk factors, injury prevention, rehabilitation, recreational running

Posted Date: December 3rd, 2019

DOI: https://doi.org/10.21203/rs.2.18112/v1

License: () (1) This work is licensed under a Creative Commons Attribution 4.0 International License. Read Full License 


\section{Abstract}

Background Knowledge about prevalence and etiology of running-related injuries (RRIs) is important to tailor an effective RRI prevention program. We aimed to investigate the prevalence and etiology of RRIs in Iranian recreational runners.

Methods An internet-based self-developed questionnaire was sent to recreational runners recruited through social media. The questionnaire asked about personal and training characteristics, psychological factors (passion, BERQ-2, RAND-36), SQUASH, sleep, foot type and RRIs over the last six months. Data were analyzed descriptively and using logistic regression.

Results Self-reported data from 804 questionnaires were analyzed. Twenty-five potential risk factors for RRIs were investigated. The male-to-female proportion was 57.5:42.5. 54\% of runners reported at least one RRI. Patellofemoral pain syndrome was the most-reported injury (19.8\%), followed by medial tibial stress syndrome (16.9\%). Knee was the most-affected location (44.6\%), followed by lower leg (19.2\%). The variables associated with RRIs were: overweight (odds ratio (OR):1.77), pes planus (OR:1.81), running over $20 \mathrm{~km} /$ week (OR:1.62), hard-surface running (OR:1.38), running company (OR:1.74), following a training program (OR:1.50), obsessive passionate attitude (OR:1.05), RAND-36 (OR:0.96), and sleep quality (OR:1.46). Associated factors for all different RRI types were analyzed too.

Conclusions Overweight, running over 20 km/week, hard-surface running, having pes planus or cavus, higher obsessive passion, lower RAND-36, and poor sleep quality were the most predictive risk factors for RRIs types. This study highlighted the importance of psychological factors besides abnormal foot arch and some trainingrelated risk factors for RRIs in Iranian runners. These results may be useful for runners and coaches to tailor effective training programs and to design RRI prevention programs that may help clinicians when managing RRIs.

\section{Introduction}

Running has become the most popular physical activity [1]. Thanks to its affordability and convenience, needing less equipment than many other sports, the number of runners has increased in recent decades [2]. Regular, leisure-time running is considered recreational. Running has many benefits, like improvement of mental and physical health: a study reported a $45 \%$ lower risk of cardiovascular mortality in runners compared to non-runners [3].

In Iran too, recreational running has become more popular because people have found it an easy and accessible way to stay healthy. This is important for Iranians ever since a recently published review about cardiovascular disease in Iran reported insufficient physical activity as one of the leading causes of the high prevalence of cardiovascular disease [4].

A major drawback of running is that it is accompanied by running-related injuries (RRIs), with incidence rates varying from $19.4 \%$ to $79 \%$, depending on the definition used and the population studied [5].

To develop preventive measures for RRI, more knowledge about etiologic factors is needed. According to the Translating Research into Injury Prevention Practice framework (TRIPP) [6], upon injury surveillance the second 
stage is establishing the etiology of injury. Accordingly, identifying and understanding causal factors for RRIs as well as the most commonly affected anatomical locations are important steps toward developing an effective prevention program [7]. There is evidence that the etiology of RRI is multifactorial and includes both extrinsic and intrinsic risk factors, some modifiable [8]. Several studies have reported risk factors predisposing runners to injuries [8-11], including abnormal biomechanics, previous injuries, training-related risk factors and insufficient running experience. However, there is still no consensus on the exact etiology of RRIs and there might even be differences between populations from different countries, regions or cultures.

Besides running/training and personal factors, RRIs may also be impacted by health, psychological, and lifestyle factors. These factors have not been explored extensively in runners yet, and not enough information on their effects on RRIs (and vice versa) is available. Recent reviews emphasize the importance of psychological factors for sports injuries [12,13], indicating that alterations in stress can predict sports injury incidence. A study has also been designed to investigate the effect of mental aspects on RRIs [14].

Recreational runners comprise the largest group of runners worldwide [15]; according to a recent systematic review, a minority of studies investigating RRIs involve recreational runners [16]. Studies mostly target runners participating in running events or organized running groups which cannot be a real-life representation of recreational runners. In Iran, recreational runners run mostly individually or in small groups. Many of them, especially women, prefer running on treadmills in indoor gyms due to religious and general beliefs.

RRIs may also have negative psychological and physical effects, and may cause individuals to quit sports or/and physical activities temporarily or even permanently [17]. RRIs can additionally result in high treatment costs and costs related to work absenteeism, which can lead to discontinuing running or reducing individual motivation [18]. Hence the need for investigating epidemiology and etiology of RRIs specifically in Iranian recreational runners is warranted.

Although several studies addressed risk factors in a small sample size of recreational runners in Iran [19-21], information about epidemiology and etiology of RRIs in Iranian recreational runners is still lacking. As the knowledge of prevalence and etiology of RRIs is the first step to effectively tailor RRI preventive programs, the aim of the current study is to describe the epidemiology, etiology and impact of RRIs among Iranian recreational runners.

\section{Methods}

\subsection{Study design}

This is a cross-sectional survey investigating the prevalence, risk factors and psychological impact of runningrelated injuries in Iranian runners using an electronic/web-based questionnaire. Ethical approval for this study was obtained from the Tehran university institutional review board (IR.SSRI. 1398.154).

\subsection{Participants}

Recreational runners were invited to participate through social media and by contacting them at sports and health departments in universities, running clubs, gyms, and sports shops in Tehran, Mashhad, and Shiraz. 
Because of their geographical differences, these cities can be considered most representative of the Iranian runners' population. A recreational runner was defined as someone who has been running for at least 9 months prior to completing the questionnaire with a minimum of $5 \mathrm{~km} /$ week and not classified as an elite runner by track and field federation. Eligibility as a recreational runner was first confirmed by a running club manager (either a university or public running club) or one of the researchers.

\subsection{Data collection}

A specific questionnaire in Farsi, tailored with the help of the "Start to Run" study questionnaire [22], with questions on personal characteristics, medical information, running characteristics, running-related injuries, and questionnaires of passion scale, RAND 36-items, BERQ-2 and SQUASH was developed using Google Form. This questionnaire was pilot-tested in 12 runners with varying running experience, after which some changes were made to arrive at the final questionnaire.

An electronic link to the online questionnaire was sent to each eligible runner. Runners were advised to consult their physicians or physiotherapists about their foot type and possible previous RRIs.

The first section of the questionnaire included eligibility criteria, instructions for completing the questionnaire, and a consent form. Upon confirming the first section, the runner could proceed with the questionnaire. The questionnaire inquired about personal characteristics, general medical information, running profiles (including running experience, weekly running distance, speed, weekly frequency, foot arch type, foot strike type, running surface, running shoes), history of RRIs over the past six months (injuries included patellofemoral pain, medial tibial stress syndrome, Achilles tendinopathy, patellar tendinopathy, iliotibial band syndrome, plantar fasciitis, strain, sprain, and meniscal or cartilage injury), and injury location. To determine injury location, a manikin chart divided into 8 major locations and 22 sub-locations was designed. The main questionnaire also included these questionnaires: obsessive passion scale; BERQ-2, assessing motivation to exercise; RAND 36-items, assessing perceived health; and SQUASH, assessing physical activity in daily life.

According to the consensus definition of RRI [23], an RRI was defined as "Running-related (training or competition) musculoskeletal pain in the lower limbs that causes a restriction on or stoppage of running (distance, speed, duration, or training) for at least 7 days or 3 consecutive scheduled training sessions, or that requires the runner to consult a physician or other health professional."

\subsection{Data analysis}

Participants' characteristics are presented in Table 1 using descriptive statistics. Mann-Whitney and Chi-square tests were used to compare data between runners with and without any history of RRIs. Since no quantitative variables were distributed normally, data were reported as median and interquartile range; categorical variables were reported as frequency and percentages. A univariate logistic regression analysis was used to assess a likely association between the risk factors and having RRI. Those variables with a $p<0.20$ were included in the multivariate logistic regression model [15] with backward elimination, whereby variables remained in the model if their associated multivariate $\mathrm{p}$-value $<0.05$. Only modifiable factors were entered into multivariate logistic regression, therefore sex and age were not entered into multivariate logistic models. To establish the 
assumption of no multicollinearity among the independent variables and enhance model fitting, the high correlated variables (obsessive passion and BERQ-2 scores $(r=0.81, p<0.001)$ were not entered together into the multivariate logistic analysis. In such cases, either variable having a lower univariate $p$-value was entered into the multivariate logistic analysis. We reported the results as odds ratios (OR) and $95 \% \mathrm{Cl}$ (confidence interval). The OR in continuous variables represents the change in odds of injury for a one-unit increase. The OR in categorical variables represents the change in odds of injury relative to referenced category determined in Table 3. Sleep quality was rated as very good (1), good (2), medium (3), poor (4), and very poor (5). The OR in sleep quality represents the change in odds of injury for a one-rank increase in sleep rating. Factors were considered risk factors if $\mathrm{OR}>1$ and protective factors if $\mathrm{OR}<1$.

\section{Results}

\subsection{Participants}

The questionnaire was filled out by 826 runners, 22 of them excluded due to missing or incorrect data. Total data from 804 questionnaires were analyzed - 644 from Tehran city, 102 from Mashhad, and 58 from Shiraz city.

\subsection{Descriptive data}

Table 1 shows the description of participants' characteristics divided into two groups, with/without injury history. Male runners comprise 57.5\% (462) of participants, female runners $42.5 \%$ (342); $80 \%$ of runners reported a BMI in the healthy range $(18<\mathrm{BMI}<25) ; 80 \%$ had $<5$ years of running experience; $59 \%$ and $70 \%$ had a running duration of up to $60 \mathrm{~min} / \mathrm{session}$ and up to 3 sessions/week, respectively; 80\% reported also participating in other sports. Most runners reported performing warm-up (92\%) and cool-down (84\%) exercises.

Table 1: Participants' characteristics

\subsection{Running injuries and location}

Table 2A shows the epidemiology of RRIs. Of the 804 runners, 432 (54\%) reported at least one RRI over the last six months; 74 reported multiple injuries (74 reported two injuries, 10 reported three injuries); 55\% (256) of male runners and 51\% (176) of female runners reported at least one RRI. Participants reported that about $89 \%$ of self-reported injuries were diagnosed by either 
a physician or a physiotherapist. In total, 516 RRIs were reported. Patellofemoral pain syndrome (PFPS) was the most-reported injury (19.8\%), followed by medial tibial stress syndrome (MTSS) (16.9\%). Table 2B shows the anatomical sites of RRIs. The knee (44\%) was the most frequently reported injury location, followed by the lower leg (19.9). Tables S1 and S2 (additional file) describe running injury type and location by gender .

Table 2: Running-related injury types* and injury location

\begin{tabular}{|c|c|c|c|c|}
\hline \multicolumn{2}{|l|}{ A. Running-related injury } & \multicolumn{3}{|c|}{ B. Location of injury } \\
\hline Injury & Total n (\%*) & Location & \multicolumn{2}{|c|}{ Total n (\%) } \\
\hline PFPS & $102(19.8)$ & Knee & \multicolumn{2}{|c|}{$230(44.6)$} \\
\hline MTSS & $87(16.9)$ & Lower leg & \multicolumn{2}{|c|}{$99(19.2)$} \\
\hline Thigh strain & $45(8.7)$ & Foot/toe & \multicolumn{2}{|c|}{$48(9.3)$} \\
\hline Meniscus or cartilage injury & $42(8.1)$ & Ankle & \multicolumn{2}{|c|}{$36(7.0)$} \\
\hline ITBS & $36(7.0)$ & \multicolumn{2}{|l|}{ Achilles } & $36(7.0)$ \\
\hline $\mathrm{AT}$ & $36(7.0)$ & \multicolumn{2}{|c|}{ Hip/groin/buttock } & $29(5.6)$ \\
\hline Ankle sprain & $35(6.8)$ & \multicolumn{2}{|c|}{ Thigh } & $23(4.5)$ \\
\hline $\mathrm{PF}$ & $28(5.4)$ & \multicolumn{2}{|l|}{ Lower back } & $15(2.9)$ \\
\hline PT & $20(3.9)$ & & & \\
\hline Knee sprain & $12(2.3)$ & & & \\
\hline Calf strain & $11(2.1)$ & & & \\
\hline Others & $62(12.0)$ & & & \\
\hline
\end{tabular}

* Proportion of any RRI in total RRIs.

Abbreviations: PFPS patellofemoral pain syndrome. MTSS medial tibial stress syndrome, ITBS iliotibial band syndrome, AT Achilles tendon injury, PF plantar fasciitis, PT patellar tendinopathy

\subsection{Running injuries and associated factors}

Table 3 shows the results of univariate logistic regression analysis between runners with and without history of injury, with each factor analyzed separately. Being overweight, running over $20 \mathrm{~km} /$ week and $60 \mathrm{~min} /$ session, performing other sports, running on hard surfaces, pes planus or cavus, a higher obsessive passion for running, and lower perceived health are the factors significantly associated with injuries $(\mathrm{p}<0.05)$.

Table 3: Results of univariate logistic regression analysis, injury versus injury-free runners 
Table 4 shows the results of multivariate logistic regression analysis of risk factors associated with each injury type. Results of multivariate logistic regression analysis for calf strain and knee sprain were reported in the additional file, table S3. Associated factors for injury were: overweight (OR 1.89, 95\%CI 1.24-2.88), running over 20 km/week (OR 1.52, 95\%CI 1.01-2.29), running company (OR 1.68, 95\%CI 1.19-2.38), following a training program (OR 1.50, 95\%CI 1.08-2.07), hard surface (OR 1.37, 95\%CI 1.18-1.59), pes planus (OR 1.85, 95\%CI 1.17-2.94), sleep quality (OR 1.48, 95\%CI 1.22-1.80), obsessive passion (OR 1.05, 95\%CI 1.03-1.07), and RAND-36 (OR 0.96, 95\%CI 0.95-0.98).

\subsection{Association between running injury types and risk factors}

Figure 1 shows the distribution of each RRI between male and female runners. Frequency of each RRI was compared between injured male and female runners using chi-square test. Men reported more AT than women $(77.8 \%$ vs $22.2 \%, \mathrm{X} 2(1, \mathrm{~N}=432)=5.58, \mathrm{p}=0.018)$ and more PT than women ( $80 \%$ vs $20 \%, \mathrm{X} 2(1, \mathrm{~N}=432)=4.73, \mathrm{p}=0.040)$; women reported more ankle sprains than men $(60 \%$ vs $40 \%, X 2(1, N=432)=5.85, p=0.016)$. No significant differences were found for frequencies of other RRI types between injured male and female runners ( $p>0.05)$.

All factors were entered separately into a univariate logistic regression with each injury type as dependent variable (additional file, Table S4-S7). The results of multivariate logistic regression are described for PFPS, MTSS, ITBS, and AT. The variables associated with PFPS were (Table 4) : running over $20 \mathrm{~km} /$ week (OR 2.34, 95\%CI 1.19-4.61), over 3 sessions/week (OR 0.33, 95\%CI 0.17-0.63), running company (OR 2.31, 95\%CI 1.36-3.93), hard surface (OR 1.40, 95\%CI 1.101.78), pes planus (OR 1.98, 95\%CI 1.02-3.85), pes cavus (OR 4.87, 95\%CI 1.83-12.0), obsessive passion (OR 1.07, 95\%CI 1.04-1.11), and RAND 36-items (OR 0.96, 95\%CI 0.94-0.98).

The final step of backward stepwise method of multivariable logistic regression for variables associated with MTSS includes (Table 4): over 3 sessions/week (OR 0.43, 95\%CI 0.22-0.83), running company (OR 2.05, 95\%CI 1.18-3.58), training program (OR 1.95, 95\%CI 1.11-3.41), pes cavus (OR 3.78, 95\%CI 1.08-13.4), hard surface (OR 1.72, 95\%CI 1.36-2.19), treadmill surface (OR 0.71, 95\%CI 0.54-0.94), sleep quality (OR 1.51, 95\%CI 1.11-2.05), obsessive passion (OR 1.05, 95\%CI 1.01-1.09), and RAND 36-items (OR 0.95, 95\%CI 0.93-0.98). 
The final step of backward stepwise method of multivariable logistic regression for variables associated with ITBS includes (Table 4): running over 20 km/week (OR 4.16, 95\%CI 1.59-10.9), sleep quality (OR 1.58, 95\%CI 1.04-2.41), obsessive passion (OR 1.05, 95\%CI 1.01-1.10), and RAND 36-items (OR 0.96, 95\%CI 0.93-1.00).

The final step of backward stepwise method of multivariable logistic regression for variables associated with AT includes (Table 4): overweight (OR 5.70, 95\%CI 2.08-15.6), pes planus (OR 4.65, 95\%CI 1.69-12.8), sleep quality (OR 3.78, 95\%CI 2.06-6.94), obsessive passion (OR 1.17, 95\%CI 1.10-1.24), and RAND 36-items (OR 0.95, 95\%CI 0.92-0.99).

Table 4: Results of multivariate logistic regression analysis* for each specific injury type 


\begin{tabular}{|c|c|c|c|c|c|c|c|c|c|c|}
\hline $\begin{array}{l}\text { Injury } \\
\text { Variables }\end{array}$ & $\begin{array}{l}\text { Injured } \\
\text { runners }\end{array}$ & PFPS & MTSS & $\begin{array}{l}\text { Thigh } \\
\text { strain }\end{array}$ & $\begin{array}{c}\text { Meniscus } \\
\text { injuries }\end{array}$ & ITBS & AT & $\begin{array}{l}\text { Ankle } \\
\text { sprain }\end{array}$ & PF & PT \\
\hline Overweight & $\begin{array}{c}1.89 \\
(1.24- \\
2.88) \\
\mathrm{p}=0.003 \\
\end{array}$ & & & & & & $\begin{array}{c}5.70 \\
(2.08- \\
15.6) \\
\mathrm{p}=0.001 \\
\end{array}$ & & $\begin{array}{c}8.66(2.49- \\
30.28) \\
p=0.001\end{array}$ & $\begin{array}{c}6.65 \\
(2.47- \\
17.9) \\
\mathrm{p}<0.001\end{array}$ \\
\hline $\begin{array}{l}\text { Over } 20 \\
\text { km/week }\end{array}$ & $\begin{array}{l}1.52 \\
(1.01- \\
2.29) \\
\mathrm{p}=0.049\end{array}$ & $\begin{array}{l}2.34 \\
(1.19- \\
4.61), \\
p=0.014\end{array}$ & & & & $\begin{array}{l}4.16 \\
(1.59- \\
10.9) \\
p=0.004 \\
\end{array}$ & & $\begin{array}{l}2.96 \\
(1.09- \\
8.06) \\
p=0.033\end{array}$ & $\begin{array}{l}8.91(2.20- \\
36.10), p=0.002\end{array}$ & \\
\hline $\begin{array}{l}2-5 \text { years' } \\
\text { experience }\end{array}$ & & & & & & & & & $\begin{array}{l}4.81(1.17- \\
19.77), p=0.030\end{array}$ & \\
\hline $\begin{array}{l}\text { Over } 5 \text { years' } \\
\text { experience }\end{array}$ & & & & & & & & & $\begin{array}{l}5.65(1.43- \\
22.39), p=0.014\end{array}$ & \\
\hline $\begin{array}{l}\text { Over } 3 \\
\text { sessions/week }\end{array}$ & & $\begin{array}{l}0.33 \\
(0.17- \\
0.63), \\
p=0.001\end{array}$ & $\begin{array}{l}0.43 \\
(0.22- \\
0.83) \\
p=0.012\end{array}$ & & & & & & & \\
\hline Warm-up & & & & & & & & $\begin{array}{l}0.20 \\
(0.07- \\
0.61) \\
p=0.004\end{array}$ & & \\
\hline $\begin{array}{l}\text { Running } \\
\text { company }\end{array}$ & $\begin{array}{l}1.68 \\
(1.19- \\
2.38) \\
p=0.003\end{array}$ & $\begin{array}{l}2.31 \\
(1.36- \\
3.93), \\
p=0.002\end{array}$ & $\begin{array}{l}2.05 \\
(1.18- \\
3.58), \\
p=0.011\end{array}$ & & & & & & & \\
\hline $\begin{array}{l}\text { Training } \\
\text { program }\end{array}$ & $\begin{array}{l}1.50 \\
(1.08- \\
2.07) \\
p=0.015\end{array}$ & & $\begin{array}{l}1.95 \\
(1.11- \\
3.41), \\
p=0.020\end{array}$ & & $\begin{array}{l}2.67 \\
(1.20- \\
5.90) \\
p=0.016\end{array}$ & & & $\begin{array}{l}0.16 \\
(0.04- \\
0.60), \\
p=0.006\end{array}$ & & \\
\hline Other sports & & & & & $\begin{array}{l}3.46 \\
(1.16- \\
10.3) \\
p=0.026 \\
\end{array}$ & & & & & \\
\hline Hard surface & $\begin{array}{l}1.37 \\
(1.18- \\
1.59) \\
\mathrm{p}<0.001 \\
\end{array}$ & $\begin{array}{l}1.40 \\
(1.10- \\
1.78), \\
p=0.006 \\
\end{array}$ & $\begin{array}{l}1.72 \\
(1.36- \\
2.19) \\
p<0.001 \\
\end{array}$ & $\begin{array}{l}1.35 \\
(1.02- \\
1.78), \\
p=0.034 \\
\end{array}$ & $\begin{array}{l}1.48 \\
(1.10- \\
2.01) \\
p=0.011\end{array}$ & & & & & \\
\hline $\begin{array}{l}\text { Treadmill } \\
\text { surface }\end{array}$ & & & $\begin{array}{l}0.71 \\
(0.54- \\
0.94), \\
p=0.015\end{array}$ & & & & & & & \\
\hline Pes planus & $\begin{array}{l}1.85 \\
(1.17- \\
2.94) \\
\mathrm{p}=0.009\end{array}$ & $\begin{array}{l}1.98 \\
(0.91- \\
3.85), \\
p=0.045\end{array}$ & & & $\begin{array}{l}3.22 \\
(1.35- \\
7.65) \\
\mathrm{p}=0.008\end{array}$ & & $\begin{array}{l}4.65 \\
(1.69- \\
12.8), \\
p=0.003\end{array}$ & $\begin{array}{l}4.99 \\
(1.95- \\
12.8), \\
p=0.001\end{array}$ & $\begin{array}{l}43.0(12.57- \\
147.1), p<0.001\end{array}$ & \\
\hline Pes cavus & & $\begin{array}{l}4.87 \\
(1.83- \\
12.0), \\
p=0.002\end{array}$ & $\begin{array}{l}3.78 \\
(1.08- \\
13.4), \\
p=0.038\end{array}$ & & & & & $\begin{array}{l}4.63 \\
(1.26- \\
17.1), \\
p=0.021\end{array}$ & & \\
\hline
\end{tabular}




\begin{tabular}{|c|c|c|c|c|c|c|c|c|c|c|}
\hline Special insole & & & & $\begin{array}{l}4.02 \\
(1.60- \\
10.1) \\
\mathrm{p}=0.003 \\
\end{array}$ & & & & & & $\begin{array}{l}4.52 \\
(1.47- \\
13.9), \\
\mathrm{p}=0.008\end{array}$ \\
\hline Sleep quality & $\begin{array}{l}1.48 \\
(1.22- \\
1.80) \\
p<0.001 \\
\end{array}$ & & $\begin{array}{l}1.51 \\
(1.11- \\
2.05), \\
\mathrm{p}=0.008\end{array}$ & & & $\begin{array}{l}1.58 \\
(1.04- \\
2.41), \\
p=0.031\end{array}$ & $\begin{array}{l}3.78 \\
(2.06- \\
6.94), \\
\mathrm{p}<0.001 \\
\end{array}$ & & & $\begin{array}{l}2.04 \\
(1.10- \\
2.79), \\
\mathrm{p}=0.024 \\
\end{array}$ \\
\hline $\begin{array}{l}\text { Obsessive } \\
\text { passion }\end{array}$ & $\begin{array}{l}1.05 \\
(1.03- \\
1.07) \\
p<0.001 \\
\end{array}$ & $\begin{array}{l}1.07 \\
(1.04- \\
1.11), \\
p<0.001 \\
\end{array}$ & $\begin{array}{l}1.05 \\
(1.01- \\
1.09), \\
\mathrm{P}=0.006\end{array}$ & & & $\begin{array}{l}1.05 \\
(1.01- \\
1.10), \\
P=0.016\end{array}$ & $\begin{array}{l}1.17 \\
(1.10- \\
1.24) \\
\mathrm{p}<0.001 \\
\end{array}$ & $\begin{array}{l}1.05 \\
(1.04- \\
1.11), \\
p=0.033\end{array}$ & $\begin{array}{l}1.11(1.05- \\
1.18) \\
p=0.001\end{array}$ & $\begin{array}{l}1.10 \\
(1.03- \\
1.16), \\
\mathrm{p}=0.003\end{array}$ \\
\hline RAND-36 & $\begin{array}{l}0.96 \\
(0.95- \\
0.98) \\
p<0.001\end{array}$ & $\begin{array}{l}0.96 \\
(0.94- \\
0.98), \\
p<0.001\end{array}$ & $\begin{array}{l}0.95 \\
(0.93- \\
0.98), \\
p<0.001\end{array}$ & $\begin{array}{l}0.95 \\
(0.93- \\
0.98) \\
p=0.001\end{array}$ & $\begin{array}{l}0.92 \\
(0.89- \\
0.95) \\
p<0.001\end{array}$ & $\begin{array}{l}0.96 \\
(0.93- \\
1.00), \\
p=0.023\end{array}$ & $\begin{array}{l}0.95 \\
(0.92- \\
0.99) \\
p=0.013\end{array}$ & $\begin{array}{l}0.95 \\
(0.92- \\
0.99), \\
p=0.008\end{array}$ & $\begin{array}{l}0.87(0.80- \\
0.94) \\
p<0.001\end{array}$ & \\
\hline
\end{tabular}

* Odds ratio (95\% CI) for categorical variables compared to the references specified in Table 3.

PFPS patellofemoral pain syndrome, MTSS medial tibial stress syndrome, ITBS iliotibial band syndrome, AT Achilles tendon injuries, PF plantar fasciitis, PT patellar tendinopathy.

\section{Discussion}

This study aimed to describe the epidemiology and etiology of RRIs specifically in Iranian recreational runners. We analyzed 804 questionnaires, 432 (54\%) reporting at least one RRIs. Male-to-female proportion was 57-43\%. Most-reported injury was PFPS (19.8\%), followed by MTSS (16.9\%). Most-affected injury location was the knee (44.6\%), followed by the lower leg (19.2\%). Of all variables analyzed together in multivariate logistic regression, overweight, running over $20 \mathrm{~km} / \mathrm{w}$, participating in other sports, having pes planus and/or cavus, poor sleep quality, greater obsessive passion, and lower RAND-36 score were associated with RRIs. Our study highlights the potential role of sleep quality, psychological factors, and the effects of abnormal foot arch in RRIs. Our findings will help researchers, trainers, clinicians, and policymakers develop preventive strategies and programs, eventually helping runners remain healthy and injury-free.

The prevalence of RRIs over the previous six months was $54 \%$, fitting with previous studies on RRIs in recreational runners reporting a $36.5 \%-79.3 \%$ prevalence $[5,15,24,25]$. The period over which injuries are reported and injury definition may affect injury incidence. Most-reported injury was PFPS, in line with previous studies [2, 26, 27]. MTSS was the second-most commonly reported RRI. Prevalence of PFPS (19.8) and MTSS (16.9) exceed other RRIs (<8.7). Men reported more AT and PT than women; women reported more ankle sprains than men. We found only one study that classified RRIs by gender, reporting more AT in men than women [28]. Knee was the most-affected injury site, with $47 \%$ of injuries attributed to a higher proportion of PFPS, fitting with previous studies identifying the knee as the most-common injured location in runners [2, 24, $26,29]$. The high knee injury rate may be attributed to the greater accumulated impact forces imposed on it when running.

Running over 20 km/w (OR 1.62-8.91) was associated with RRIs, which implies that runners may reduce their weekly running distance to a lower level of $20 \mathrm{~km} /$ w to prevent RRI. However, it seems that a safe running 
distance may vary between populations and is related to other training factors. Contradictory results have been reported so far on running distance. A systematic review investigating RRIs did not reach agreement on the most appropriate and safe running distance [30].

Running on hard surfaces had between 1.35 and 1.72 higher odds of RRIs. Two studies highlighted hardsurface running as a risk for RRIs [27,31]. By contrast, a prospective study reported that hard surface is not associated with RRIs in recreational runners [15]. Our results showed that hard-surface running was one of the contributing factors for the four most common RRIs. These results may account for hard-surface running causing greater musculoskeletal stress to the lower limbs than any other surface [32]. About $82 \%$ of participants reported at least one session/week running on asphalt and/or cement, surfaces that are most easily accessible. Results showed that treadmill running seems to result in less MTSS (OR 0.71), maybe because it reduces the total stress on lower leg musculoskeletal system compared to hard surfaces. Sub-group analyses indicated that female runners reported more treadmill sessions per week than men. About $62 \%$ of women reported at least one treadmill session/week, compared to $35 \%$ of men. Iranian female recreational runners usually prefer indoor running due to religious beliefs or hijab rules, making treadmills the best accessible indoor running option. Treadmill running was not a significant factor for other RRI types.

Besides physical demands, mental aspects also play an important role in sports performance such as running. These psychological factors affect both injury incidence [33] and injury rehabilitation [34]. Psychological factors influence training variables such as the training loads that a runner can tolerate before incurring an injury [35]. Our results showed that runners reporting a history of injury had more obsessive passion for running than those without such history. More importantly, obsessive passion or BERQ-2 (high correlation with obsessive passion in our study) was one of the factors associated with most RRIs. The effect of obsessive passion gained significance when an analysis of our participants revealed that runners reporting multiple injuries scored significantly higher obsessive passion than those with one injury. In fact, obsessive passion drives runners to keep on running while injured. This can lead to multiple and chronic injuries. Our results are in line with a previous study showing that long-distance runners with more obsessive passion were more prone to injury [36]. Because of their obsessive passion for running these runners do not sufficiently weigh the situation and circumstances leading to running excesses, thereby predisposing themselves to RRIs.

Injuries might have an impact on general well-being [37]. We also found an association between perceived health and RRIs. Runners with a history of injury reported lower RAND 36-item scores than those without any such history. A reduced RAND-36 score was shown for all types of RRIs (except for PT). Our analysis showed that injured female runners reported significantly lower perceived health than injured male runners. Injuries are speculated to have more health effects in women than men, or women with lower perceived health are more prone to injury than men. Due to our study design, it remains unclear whether the lower perceived health is cause or consequence of the RRI.

Our results also showed that poor sleep quality is associated with increasing RRIs odds by 3.78. Previous studies highlighted lack of sleep as a risk factor for sports injuries [38-41] while considering quantification of sleep. It seems that exploring sleep quality, as measured in our study, can be more relevant to studying sports injuries than exploring sleep quantity. Good sleep quality is necessary for skeletal musculature to adapt, repair, 
and increase [38] concentration to better perform a sports activity like running, while poor sleep quality can reduce these factors and leads to injuries [39].

Pes planus and cavus are significantly associated with most of the RRIs. Runners with pes planus compared to those with normal feet had an odds ratio of 1.7 for MTSS to 43 for PF; those with pes cavus compared to normal feet had an odds ratio of 4.63 for ankle sprain to 4.87 for PFPS. A subgroup analysis revealed that about $50 \%$ of runners reporting multiple injuries had either pes planus or pes cavus. Previous studies also highlighted the importance of foot arch for RRIs [42-44]. A recent study showed that pes planus and cavus are associated with 20 to 77 times higher odds of RRIs than normal feet, respectively [43]. A systematic review reported that pes planus and cavus are associated with lower-limb injuries [45]. Another systematic review reported strong and limited evidence that pes planus is a risk factor for MTSS and PFPS, respectively [46].

Running in a group was associated by 2.3 times higher odds of reporting injuries. Nevertheless, it is difficult to conclude the causative effect of the association between running in a group or alone and RRIs. Our results showed that about $61 \%$ of runners who ran in a group followed a training program. Also, those following a training program showed higher odds of RRIs and MTSS. Group runners most likely follow the same training program. It could therefore be concluded that following the same group running program may increase the odds of RRIs. This indeed underlines the individuality principle in sports training. We therefore recommend individualization of training programs for runners.

\subsection{Limitations and recommendations for future studies}

Our survey results should be interpreted with caution. This is a retrospective study, so it is difficult to determine the causative association between risk factors and RRIs. Recall bias could also be a limitation of our study because all data were collected using a self-reported questionnaire. Although $89 \%$ of injuries and $60 \%$ of foot types were diagnosed by a physician or physiotherapist, which we believe increases the accuracy of data, injuries and foot type were self-reported. We also provided runners with a clear definition for each RRI to minimize this bias. Future prospective studies are warranted among Iranian recreational runners to substantiate RRI risk factors obtained from our study.

\subsection{Practical implications}

Our study describes potential risk factors for RRIs in Iranian recreational runners, which may be useful toward preventing and managing RRIs. Our findings are also important for runners who want to be aware of factors predisposing them to developing an RRI. These factors may be considered when preventing and/or managing RRIs: 1) correcting pes planus and cavus, 2) avoiding or reducing running on hard surfaces, 3) counseling for obsessive passion for running to avoid overdoing it, 4) controlling running distance, 5) personalizing the training program, 6) improving overall physical and mental health, and 7) enhancing sleep quality.

\section{Conclusion}

In Iranian runners too, the prevalence of RRIs is high. PFPS (19.8\%) and MTSS (16.9\%) were the most-reported injuries. Having pes planus or cavus, being overweight, running over $20 \mathrm{~km} /$ week, greater obsessive passion for 
running, hard-surface running, lower perceived health, and poor sleep quality were the most important factors associated with RRIs. Our results highlight the complex and multifactorial nature of RRIs. Personalizing preventive and educational programs are important toward reducing the number of RRIs.

\section{List Of Abbreviations}

$R R / s$ running-related injuries, OR odds ratio, C/confidence interval, PFPS patellofemoral pain syndrome, MTSS medial tibial stress syndrome, ITBS iliotibial band syndrome, AT Achilles tendon injuries, $P F$ plantar fasciitis, $P T$ patellar tendinopathy.

\section{References}

1. Rothschild CE. Primitive running: a survey analysis of runners' interest, participation, and implementation. J strength Cond Res. 2012;26:2021-6. doi:10.1519/JSC.0b013e31823a3c54.

2. Lopes AD, Hespanhol Junior LC, Yeung SS, Costa LO. What are the main running-related musculoskeletal injuries? A Systematic Review. Sport Med. 2012;42:891-905.

3. Lee D-C, Pate RR, Lavie CJ, Sui X, Church TS, Blair SN. Leisure-time running reduces all-cause and cardiovascular mortality risk. J Am Coll Cardiol. 2014;64:472-81. doi:10.1016/j.jacc.2014.04.058.

4. Sarrafzadegan N, Mohammmadifard N. Cardiovascular disease in Iran in the last 40 years: Prevalence, mortality, morbidity, challenges and strategies for cardiovascular prevention. Arch Iran Med. 2019;22:20410.

5. Van Gent RN, Siem D, Van Middeloop M, Van Os AG, Bierma-Zeinstra SMA, Koes BW. Incidence and determinants of lower extremity running injuries in long distance runners: A systematic review. Sport en Geneeskd. 2007;40:16-29.

6. Finch C. A new framework for research leading to sports injury prevention. Journal of Science and Medicine in Sport. 2006;9:3-9.

7. van Mechelen W, Hlobil H, Kemper HC. Incidence, severity, aetiology and prevention of sports injuries. A review of concepts. Sport Med. 1992;14:82-99.

8. Gijon-Nogueron G, Fernandez-Villarejo M. Risk factors and protective factors for lower-extremity running injuries: A systematic review. J Am Podiatr Med Assoc. 2015;105:532-40. doi:10.7547/14-069.1.

9. Ceyssens $L$, Vanelderen R, Barton C, Malliaras P, Dingenen B. Biomechanical risk factors associated with running-related injuries: A systematic review. Sports Med. 2019;49:1095-115. doi:10.1007/s40279-01901110-z.

10. Mousavi SH, Hijmans JM, Rajabi R, Diercks R, Zwerver J, van der Worp H. Kinematic risk factors for lower limb tendinopathy in distance runners: A systematic review and meta-analysis. Gait Posture. 2019;69:1324. doi:10.1016/j.gaitpost.2019.01.011.

11. Van Der Worp MP, Ten Haaf DSM, Van Cingel R, De Wijer A, Nijhuis-Van Der Sanden MWG, Bart Staal J. Injuries in runners; a systematic review on risk factors and sex differences. PLoS One. 2015;10:1-18.

12. Ivarsson A, Johnson U, Andersen MB, Tranaeus U, Stenling A, Lindwall M. Psychosocial factors and sport Injuries: Meta-analyses for prediction and prevention. Sports Med. 2017;47:353-65. doi:10.1007/s40279016-0578-x. 
13. Johnson U, Ivarsson A. Psychosocial factors and sport injuries: prediction, prevention and future research directions. Current Opinion in Psychology. 2017;16:89-92.

14. De Jonge J, Van Iperen L, Gevers J, Vos S. "Take a Mental Break!” study: Role of mental aspects in runningrelated injuries using a randomised controlled trial. BMJ Open Sport Exerc Med. 2018;4.

15. Hespanhol Junior LC, Pena Costa LO, Lopes AD. Previous injuries and some training characteristics predict running-related injuries in recreational runners: A prospective cohort study. J Physiother. 2013;59:263-9.

16. Kluitenberg B, van Middelkoop M, Diercks R, van der Worp $H$. What are the differences in injury proportions between different populations of runners? A systematic review and meta-analysis. Sport Med. 2015;45:1143-61.

17. Fokkema T, Hartgens F, Kluitenberg B, Verhagen E, Backx FJG, van der Worp H, et al. Reasons and predictors of discontinuation of running after a running program for novice runners. J Sci Med Sport. 2019;22:106-11. doi:10.1016/j.jsams.2018.06.003.

18. Hespanhol Junior LC, Pillay JD, van Mechelen W, Verhagen E. Meta-analyses of the effects of habitual running on indices of health in physically inactive adults. Sport Med. 2015;45:1455-68. doi:10.1007/s40279-015-0359-y.

19. Nejati P, Forogh B, Moeineddin R, Baradaran HR, Nejati M. Patellofemoral pain syndrome in Iranian female athletes. Acta Med Iran. 2011;49:169-72.

20. Ilbeigi S, Mirzanejand S, Eslami M, Tajik A. The comparison of standard and local shoes on the variables related to tibia stress fracture in male student recreational runners. Razi J Med Sci. 2016;23:56-63.

21. Anbarian M, Esmaili $H$. The effect of running-induced fatigue on foot roll-over pattern in novice runners. $J$ Paramed Sci Rehabil. 2016;5.

22. Smits DW, Huisstede B, Verhagen E, Van Der Worp H, Kluitenberg B, Van Middelkoop M, et al. Short-term absenteeism and health care utilization due to lower Extremity injuries among novice runners: $\mathrm{A}$ prospective cohort study. Clin J Sport Med. 2016;26:502-9.

23. Yamato TP, Saragiotto BT, Lopes AD. A consensus definition of running-related injury in recreational runners: A modified delphi approach. J Orthop Sport Phys Ther. 2015;45:375-80. doi:10.2519/jospt.2015.5741.

24. Hespanhol Junior LC, de Carvalho ACA, Costa LOP, Lopes AD. Lower limb alignment characteristics are not associated with running injuries in runners: Prospective cohort study. Eur J Sport Sci. 2016;16:1137-44. doi:10.1080/17461391.2016.1195878.

25. Borel WP, Filho JE, Diz JBM, Moreira PF, Veras PM, Catharino LL, et al. Prevalence of injuries in brazilian recreational street runners: Meta-analysis. Rev Bras Med do Esporte. 2019;25:161-7.

26. Francis $P$, Whatman $C$, Sheerin K, Hume P, Johnson MI. The Proportion of lower limb running injuries by gender, anatomical location and specific pathology: A systematic review. J Sports Sci Med. 2019;18:2131.

27. Hespanhol Junior LC, Costa LOP, Carvalho ACA, Lopes AD. A description of training characteristics and its association with previous musculoskeletal injuries in recreational runners: a cross-sectional study. Brazilian J Phys Ther. 2012;16:46-53.

28. McKean, K. A.; Manson, N. A.; Stanish WD. Gender differences in running injuries. In: Clinical Journal of Sport Medicine. 2004. p. 377. 
29. Linton L, Valentin S. Running with injury: A study of UK novice and recreational runners and factors associated with running related injury. J Sci Med Sport. 2018;21:1221-5.

30. Nielsen RO, Buist I, Sørensen H, Lind M, Rasmussen S. Training errors and running related injuries: a systematic review. Int J Sports Phys Ther. 2012;7:58-75.

31. Wen DY, Puffer JC, Schmalzried TP. Lower extremity alignment and risk of overuse injuries in runners. Med Sci Sports Exerc. 1997;29:1291-8.

32. Tessutti V, Ribeiro AP, Trombini-Souza F, Sacco ICN. Attenuation of foot pressure during running on four different surfaces: Asphalt, concrete, rubber, and natural grass. J Sports Sci. 2012;30:1545-50.

33. Wiese-Bjornstal DM. Psychological predictors and consequences of injuries in sport settings. In: APA handbook of sport and exercise psychology, volume 1: Sport psychology (Vol. 1). American Psychological Association; 2019. p. 699-725.

34. Ardern CL, Taylor NF, Feller JA, Webster KE. A systematic review of the psychological factors associated with returning to sport following injury. British Journal of Sports Medicine. 2013;47:1120-6.

35. Vallerand RJ. Chapter Three: On passion for life activities: The dualistic model of passion. 1st edition. Elsevier Inc.; 2010. doi:10.1016/S0065-2601(10)42003-1.

36. Stephan Y, Deroche T, Brewer BW, Caudroit J, Le Scanff C. Predictors of perceived susceptibility to sportrelated injury among competitive runners: The role of previous experience, neuroticism, and passion for running. Appl Psychol. 2009;58:672-87.

37. Raysmith BP, Drew MK. Performance success or failure is influenced by weeks lost to injury and illness in elite Australian track and field athletes: A 5-year prospective study. J Sci Med Sport. 2016;19:778-83. doi:10.1016/j.jsams.2015.12.515.

38. Gao B, Dwivedi S, Milewski MD, Cruz Al. Chronic lack of sleep is associated with increased sports injuries in adolescent: A systematic review and meta analysis. Orthop J Sport Med. 2019;7

3_suppl:2325967119S0013.

39. Milewski MD, Skaggs DL, Bishop GA, Pace JL, Ibrahim DA, Wren TAL, et al. Chronic lack of sleep is associated with increased sports injuries in adolescent athletes. J Pediatr Orthop. 2014;34:129-33. doi:10.1097/BPO.0000000000000151.

40. Luke A, Lazaro RM, Bergeron MF, Keyser L, Benjamin H, Brenner J, et al. Sports-related injuries in youth athletes: Is overscheduling a risk factor? Clin J Sport Med. 2011;21:307-14.

41. von Rosen P, Frohm A, Kottorp A, Fridén C, Heijne A. Too little sleep and an unhealthy diet could increase the risk of sustaining a new injury in adolescent elite athletes. Scand J Med Sci Sports. 2017;27:1364-71. doi:10.1111/sms.12735.

42. Kaufman KR, Brodine SK, Shaffer R a, Johnson CW, Cullison TR. The effect of foot structure and range of motion on musculoskeletal overuse injuries. Am J Sports Med. 1999;27:585-93.

43. Pérez-Morcillo A, Gómez-Bernal A, Gil-Guillen VF, Alfaro-Santafé J, Alfaro-Santafé JV, Quesada JA, et al. Association between the foot posture index and running related injuries: A case-control study. Clin Biomech. 2019;61:217-21. doi:10.1016/j.clinbiomech.2018.12.019.

44. Williams DS, McClay IS, Hamill J. Arch structure and injury patterns in runners. Clin Biomech (Bristol, Avon). 2001;16:341-7. http://www.ncbi.nlm.nih.gov/pubmed/11358622. Accessed 2 Aug 2019. 
45. Tong JWK, Kong PW. Association between foot type and lower extremity injuries: systematic literature review with meta-analysis. J Orthop Sports Phys Ther. 2013;43:700-14. doi:10.2519/jospt.2013.4225.

46. Neal BS, Griffiths IB, Dowling GJ, Murley GS, Munteanu SE, Franettovich Smith MM, et al. Foot posture as a risk factor for lower limb overuse injury: a systematic review and meta-analysis. J Foot Ankle Res. 2014;7:1-13.

\section{Declarations}

\section{Ethics approval and consent to participate}

Ethical approval for this study was obtained from the Tehran university institutional review board (IR.SSRI. 1398.154). Consent to participate was given before completing the questionnaire.

\section{Consent for publication}

Not applicable.

\section{Availability of data and materials}

The datasets used and/or analyzed during the current study are available from the corresponding author on reasonable request.

\section{Competing interests}

The authors declare that they have no competing interests.

\section{Acknowledgements}

Not applicable.

\section{Funding}

Not applicable.

\section{Authors' contributions}

SHM participated in the study design, making the questionnaire, recruitment, data collection, analysis and interpretation of the data, drafting, and final preparation of the manuscript. JZ and JH participated in the study design, making the questionnaire, analysis and interpretation of the data, drafting, and final revising of the manuscript. RR and HM participated in the study design, making the questionnaire, recruitment, data collection, drafting, and final revising of the manuscript. BA participated in the study design, analysis and interpretation of the data, drafting, and final preparation of the manuscript. All authors have read and approved the final manuscript.

\section{Tables}

Table 1: Participants' characteristics 


\begin{tabular}{|c|c|c|c|c|}
\hline Variable & $\begin{array}{l}\text { Total participants } \\
(\mathrm{n}=804)\end{array}$ & $\begin{array}{l}\text { Participants with injury } \\
\text { history }(n=432)\end{array}$ & $\begin{array}{l}\text { Participants without injury } \\
\text { history }(n=372)\end{array}$ & P-value \\
\hline \multicolumn{4}{|l|}{ Sex (male/female) } & \multirow{3}{*}{0.27} \\
\hline Female, n (\%) & $342(42.5)$ & $176(40.7)$ & $166(44.6)$ & \\
\hline Male, n (\%) & $462(57.5)$ & $256(59.3)$ & $206(55.4)$ & \\
\hline Total, n (\%) & 804 & $432(54)$ & $372(46)$ & \\
\hline Age (years) & $27(11)$ & $27(12)$ & $27(12)$ & 0.48 \\
\hline BMI $\left(\mathrm{kg} / \mathrm{m}^{2}\right)$ & $23(3.6)$ & $23(3.9)$ & $23(3.4)$ & 0.8 \\
\hline Normal, n (\%) & $644(80.1)$ & $336(77.8)$ & $308(82.8)$ & \multirow[t]{3}{*}{0.087} \\
\hline Overweight, n (\%) & $150(18.7)$ & $92(21.3)$ & $58(15.6)$ & \\
\hline Obese, n (\%) & $10(1.2)$ & $4(0.9)$ & $6(1.6)$ & \\
\hline $\begin{array}{l}\text { Running experience } \\
\text { (years) }\end{array}$ & $2(4)$ & $2(4)$ & $2(3.2)$ & 0.49 \\
\hline Up to $2, \mathrm{n}(\%)$ & $452(56.2)$ & $244(56.5)$ & $208(55.9)$ & \multirow[t]{3}{*}{0.109} \\
\hline Between $2 \& 5, \mathrm{n}(\%)$ & $198(24.6)$ & $96(22.2)$ & $102(27.4)$ & \\
\hline Over $5, \mathrm{n}(\%)$ & $154(19.2)$ & $92(21.3)$ & $62(16.7)$ & \\
\hline $\begin{array}{l}\text { Running distance } \\
\text { (km/week) }\end{array}$ & $15(15)$ & $15(20)$ & $15(10)$ & 0.04 \\
\hline Up to $10, \mathrm{n}(\%)$ & $298(37.1)$ & $148(34.3)$ & $150(40.3)$ & \multirow[t]{3}{*}{0.002} \\
\hline $\begin{array}{l}\text { Between } 10 \& 20, \mathrm{n} \\
(\%)\end{array}$ & $266(33.1)$ & $132(30.6)$ & $134(36.0)$ & \\
\hline Over $20, \mathrm{n}(\%)$ & $240(29.9)$ & $152(35)$. & $88(23.7)$ & \\
\hline $\begin{array}{l}\text { Running sessions } \\
\text { (No/week) }\end{array}$ & $3(2)$ & $3(2)$ & $3(2)$ & 0.146 \\
\hline Up to $3, \mathrm{n}(\%)$ & $558(69.4)$ & $304(70.4)$ & $254(68.3)$ & \multirow[t]{2}{*}{0.52} \\
\hline Over 3, n (\%) & $246(30.6)$ & $128(29.6)$ & $118(31.7)$ & \\
\hline $\begin{array}{l}\text { Running duration } \\
\text { (min/session) }\end{array}$ & $45(30)$ & $45(30)$ & $40(30)$ & $<0.001$ \\
\hline Up to $60, \mathrm{n}(\%)$ & $476(59.2)$ & $235(54.4)$ & $241(64.8)$ & \multirow[t]{2}{*}{0.003} \\
\hline Over $60, \mathrm{n}(\%)$ & $358(40.8)$ & $197(45.6)$ & $131(35.2)$ & \\
\hline \multicolumn{5}{|l|}{ Running surface \# } \\
\hline Hard & $1(1)$ & $2(1)$ & $1(1)$ & $<0.001$ \\
\hline Soft & $0(0)$ & $0(0)$ & $0(0)$ & 0.92 \\
\hline Treadmill & $0(1)$ & $0(1)$ & $0(0)$ & 0.10 \\
\hline Others & $0(0)$ & $0(0)$ & $0(0)$ & 0.43 \\
\hline \multicolumn{5}{|l|}{ Other sports } \\
\hline Yes, n (\%) & $642(79.9)$ & $358(82.9)$ & $284(76.3)$ & \multirow[t]{2}{*}{0.021} \\
\hline No, $\mathrm{n}(\%)$ & $162(20.1)$ & $74(17.1)$ & $88(23.7)$ & \\
\hline \multicolumn{5}{|l|}{ Warm-up } \\
\hline Yes, n (\%) & $740(92)$ & $392(90.7)$ & $348(93.5)$ & \multirow{2}{*}{0.143} \\
\hline No, n (\%) & $64(8)$ & $40(9.3)$ & $24(6.5)$ & \\
\hline \multicolumn{5}{|l|}{ Cool-down } \\
\hline Yes, n (\%) & $672(83.6)$ & $362(83.8)$ & $310(83.3)$ & \multirow{2}{*}{0.86} \\
\hline No, n (\%) & $132(16.4)$ & $70(16.2)$ & $62(16.7)$ & \\
\hline Foot type & \multicolumn{3}{|c|}{$62(7.7 \%)$ reported "do not know" } & \\
\hline Normal, n (\%) & $564(70.1)$ & $282(65.3)$ & $282(75.8)$ & \multirow{3}{*}{$<0.001$} \\
\hline Pes planus, $\mathrm{n}(\%)$ & $131(16.3)$ & $89(20.6)$ & $42(11.3)$ & \\
\hline Pes cavus, n (\%) & $47(5.8)$ & $35(8.1)$ & $12(3.2)$ & \\
\hline \multicolumn{5}{|l|}{ Special shoes } \\
\hline No, n (\%) & $248(30.8)$ & $124(33.3)$ & $124(28.7)$ & \multirow{2}{*}{0.21} \\
\hline Yes, n (\%) & $556(69.2)$ & $248(66.7)$ & $308(71.3)$ & \\
\hline
\end{tabular}




\begin{tabular}{|c|c|c|c|c|}
\hline \multicolumn{5}{|l|}{ Special insole } \\
\hline No, n (\%) & 687 (85.4) & 359 (83.1) & $328(88.2)$ & \multirow{2}{*}{0.042} \\
\hline Yes, n (\%) & $117(14.6)$ & $73(16.9)$ & $44(11.8)$ & \\
\hline \multicolumn{5}{|l|}{ Running company } \\
\hline Group, n (\%) & $252(31.3)$ & $146(33.8)$ & $106(28.5)$ & \multirow{2}{*}{0.11} \\
\hline Alone, n (\%) & $552(68.7)$ & $286(66.2)$ & $266(71.5)$ & \\
\hline \multicolumn{5}{|l|}{$\begin{array}{l}\text { Following a running } \\
\text { program }\end{array}$} \\
\hline No, n (\%) & $424(52.7)$ & $213(49.3)$ & $211(56.7)$ & \multirow{2}{*}{0.036} \\
\hline Yes, n (\%) & $380(47.3)$ & $219(50.7)$ & $161(43.3)$ & \\
\hline Foot strike & \multicolumn{3}{|c|}{$32(4 \%)$ reported "do not know" } & \\
\hline Rearfoot, n (\%) & $432(53.7)$ & $224(51.9)$ & $208(55.9)$ & \multirow{3}{*}{0.205} \\
\hline Midfoot, n (\%) & $192(23.9)$ & $116(26.9)$ & $76(20.4)$ & \\
\hline Forefoot, n (\%) & $148(18.4)$ & $76(17.6)$ & $72(19.4)$ & \\
\hline \multicolumn{5}{|l|}{ Sleep quality } \\
\hline Very good & $162(20.1)$ & $64(14.8)$ & $98(26.3)$ & \multirow[t]{5}{*}{$<0.001$} \\
\hline Good & $360(44.8)$ & $178(41.2)$ & $182(48.9)$ & \\
\hline Moderate & $208(25.9)$ & $134(31.0)$ & $74(19.9)$ & \\
\hline Poor & $6498.0)$ & $48(11.1)$ & $16(4.3)$ & \\
\hline Very poor & $10(1.2)$ & $8(1.9)$ & $2(0.5)$ & \\
\hline Obsessive passion & $17(11)$ & $19(13)$ & $15.5(10)$ & $<0.001$ \\
\hline $\begin{array}{l}\text { RAND-36 } \\
\text { questionnaire }\end{array}$ & $80(15.25)$ & $78(16.5)$ & $82.13(12)$ & $<0.001$ \\
\hline BERQ-2 questionnaire & $11.4(10)$ & $11.4(3.6)$ & $11.4(4.4)$ & 0.594 \\
\hline SQUASH & $4822.5(5370)$ & $4770(4924)$ & $4867.5(6630)$ & 0.751 \\
\hline
\end{tabular}

Continuous data are expressed as medians and interquartile ranges (tested by the Mann-Whitney test). All categorical data are expressed by number of runners and percentages (using Chi-square test). Type of surface: hard (cement, asphalt), treadmill, soft (gravel, grass, off-road track), and other (synthetic, sand). Bold P-value shows the statistically significant difference between those with and without injury history $(\mathrm{P}<0.05)$.

Table 3: Results of univariate logistic regression analysis, injury versus injury-free runners 


\begin{tabular}{|c|c|c|}
\hline Variable & OR $(95 \% \mathrm{CI})$ & $\mathrm{P}$ \\
\hline Sex $\left(\right.$ male $\left.^{R}\right)$ & $0.85(0.65-1.13)$ & 0.27 \\
\hline Age & $1.0(0.98-1.02)$ & 0.97 \\
\hline \multicolumn{3}{|l|}{ BMI } \\
\hline Normal $^{\mathrm{R}}$ & Reference & \\
\hline Overweight & $1.45(1.01-2.09)$ & $0.043^{*}$ \\
\hline Obese & $0.61(0.17-2.19)$ & 0.45 \\
\hline \multicolumn{3}{|l|}{ Running Experience (years) } \\
\hline Up to $2^{\mathrm{R}}$ & Reference & \\
\hline Between $2 \& 5$ & $0.80(0.57-1.12)$ & 0.20 \\
\hline Over 5 & $1.27(0.87-1.83)$ & 0.22 \\
\hline \multicolumn{3}{|l|}{ Running distance (km) } \\
\hline Up to $10^{\mathrm{R}}$ & Reference & \\
\hline Between $10 \& 20$ & $1.0(0.72-1.39)$ & 0.99 \\
\hline Over 20 & $1.75(1.24-2.48)$ & $0.002^{*}$ \\
\hline \multicolumn{3}{|l|}{ Training sessions (No/pw) } \\
\hline Up to $3^{\mathrm{R}}$ & Reference & \\
\hline Over 3 & $0.91(0.67-1.22)$ & 0.52 \\
\hline \multicolumn{3}{|c|}{ Running duration (min/session) } \\
\hline Up to $60^{\mathrm{R}}$ & Reference & \\
\hline Over 60 & $1.54(1.16-2.05)$ & $0.003^{*}$ \\
\hline Other sports (No ${ }^{\mathrm{R}}$ ) & $1.50(1.06-2.12)$ & $0.022^{*}$ \\
\hline \multicolumn{3}{|l|}{ Training surface } \\
\hline Hard & $1.30(1.14-1.48)$ & $<0.001^{*}$ \\
\hline Soft & $0.95(0.78-1.15)$ & 0.60 \\
\hline Treadmill & $0.88(0.75-1.02)$ & $0.08^{*}$ \\
\hline Others & $1.11(0.90-1.41)$ & 0.35 \\
\hline Warm-up (yes ${ }^{\mathrm{R}}$ ) & $1.48(0.87-2.50)$ & $0.15^{*}$ \\
\hline Cool-down (yes ${ }^{\mathrm{R}}$ ) & $0.97(0.67-1.41)$ & 0.86 \\
\hline \multicolumn{3}{|l|}{ Foot type } \\
\hline Normal $^{\mathrm{R}}$ & Reference & \\
\hline Pes planus & $2.12(1.42-3.17)$ & $<0.001^{*}$ \\
\hline Pes cavus & $2.92(1.48-5.74)$ & $0.002^{*}$ \\
\hline Special shoes (yes ${ }^{\mathrm{R}}$ ) & $1.24(0.92-1.68)$ & $0.16^{*}$ \\
\hline Special insole (yes ${ }^{\mathrm{R}}$ ) & $1.32(1.03-2.27)$ & $0.11^{*}$ \\
\hline Running company (alone ${ }^{\mathrm{R}}$ ) & $1.28(0.95-1.73)$ & $0.11^{*}$ \\
\hline Running program (no ${ }^{\mathrm{R}}$ ) & $1.35(1.02-1.78)$ & $0.036^{*}$ \\
\hline \multicolumn{3}{|l|}{ Foot strike } \\
\hline Rearfoot $^{\mathrm{R}}$ & Reference & \\
\hline Midfoot & $1.22(0.94-2.00)$ & $0.088^{*}$ \\
\hline Forefoot & $0.98(0.68-1.42)$ & 0.92 \\
\hline Poor sleep quality & $1.68(1.42-1.98)$ & $<0.001^{*}$ \\
\hline Obsessive passion & $1.04(1.02-1.06)$ & $<0.001^{*}$ \\
\hline RAND-36 questionnaire & $0.97(0.95-0.98)$ & $<0.001^{*}$ \\
\hline BERQ-2 questionnaire & $1.04(0.99-1.08)$ & $0.13^{*}$ \\
\hline SQUASH & $1.00(1.00-1.00)$ & 0.43 \\
\hline
\end{tabular}

$\mathrm{R}$ reference values

* variables entered into multivariate logistic analysis for injured vs. non-injured runners. 
Bold P-value shows the statistically significant association between the respective variable (independent variable) and injured vs. non-injured group (dependent variable) $(\mathrm{P}<0.05)$.

\section{Supplementary Files}

This is a list of supplementary files associated with this preprint. Click to download.

- Additionalfile.docx 